\title{
A Study of the Differences about Chinese Qixi Festival Custom - Taking Shanxi's Old Local Chronicles as an Example
}

\author{
Bei Zhang (Corresponding author) \\ Department of School of Humanities, Southwest Jiaotong University \\ PO Box 611756, Chengdu, Sichuan, China \\ E-mail: dxxtuzi@163.com
}

Received: January 4, 2021 Accepted: January 30, 2021 Published: February 5, 2021

doi:10.5296/ijch.v8i1.18154 URL: https://doi.org/10.5296/ijch.v8i1.18154

\begin{abstract}
The Qixi Festival is a traditional festival in China, which inherits the production model of male farming and female weaving for thousands of years. It is considered as a symbol of Chinese farming culture and widely propagated in many provinces in China since a long time ago. However, people in different areas celebrate this festival in different ways during different periods. This can be found in the documents that recorded in local chronicles.

This research takes Shanxi Province as an example. Through sorting out 72 types of local chronicles that recorded the contents of the Qixi Festival which compiled during the Qing Dynasty and the Republic of China, we found that the differences mainly manifested in four aspects: the gender and age of the participants, the objects of sacrifice, the sacrificial offering, and the behavior of begging dexterousness. Through analyzing, it can be seen that these differences are caused by the impact of the environment, production mode, economic structure, and also related to the integration multiple cultural elements in the festival itself.
\end{abstract}

Keywords: the Qixi Festival, Local Chronicles, Shanxi Province

\section{The Origin and Custom of the Qixi Festival}

The Qixi Festival which originated very early in China had become popular in the Han Dynasty. There have been relevant records in a large number of ancient Chinese books such as Xijing Zaji (西京杂记) and Fengtu Ji (风土记). This festival has widely spread in many provinces and was included in the first batch of intangible cultural heritage listed in China in 


\section{$\triangle 1$ Macrothink}

International Journal of Culture and History

ISSN 2332-5518

2021, Vol. 8, No. 1

2006. Qixi is the night of the seventh day of July in Chinese lunar calendar. People celebrate this festival by praying for dexterousness for Niulang (牛郎) and Zhinv (织女). It inherits based on the production mode of male farming and female weaving, which has existed for thousands of years in China. It is regard as a symbol of Chinese farming culture.

Zhinv and Niulang originally referred to the stars in the sky and that could be found in Shijing (诗经), Xingjing (星经) and other ancient books. There are two portraits in the astronomical relief stone of the Han Dynasty, as shown in Figure 1. Since the Han Dynasty, these two stars had gradually personified and become two characters in myths and legends. It was said that Zhinv was the goddess who was responsible for weaving in the heavenly court. Niulang was also a god in the early myths. However, during the Wei and Jin Periods he became a poor guy gradually who grazed cattle in village. In the beginning this legend was similar as the Swan virgin story. Then it absorbed the element of the story of Dongyong and the Seventh Fairy (董永和七仙女). Nowadays, the main content of this legend is as follows: Zhinv and Niulang fell in love with each other but were forced to separate by the Tianhe (天 河, the galaxy) in a whole year. Only by climbing a bridge that build by magpies on the day of the Qixi Festival can they see each other for several hours. People were moved by their love story and sympathized with their experiences. So people commemorated the couple in many ways this day. Women often beg for a happy marriage in this evening, which makes it regarded as "Chinese Valentine's Day" today. On the other hand, because Zhinv is good at weaving so people believe that if pray to her they can also become as dexterous as her. So this festival is also called "Qiqiao Festival" (a festival that people can beg for cleverness and dexterousness). In addition to sacrifices and prayers, the folks also hold a competition of threading, taking divination about the dexterousness. In short, the ancient Chinese people attached great importance to the Qixi Festival and enjoyed it very much, as shown in Figure 2 and Figure 3.

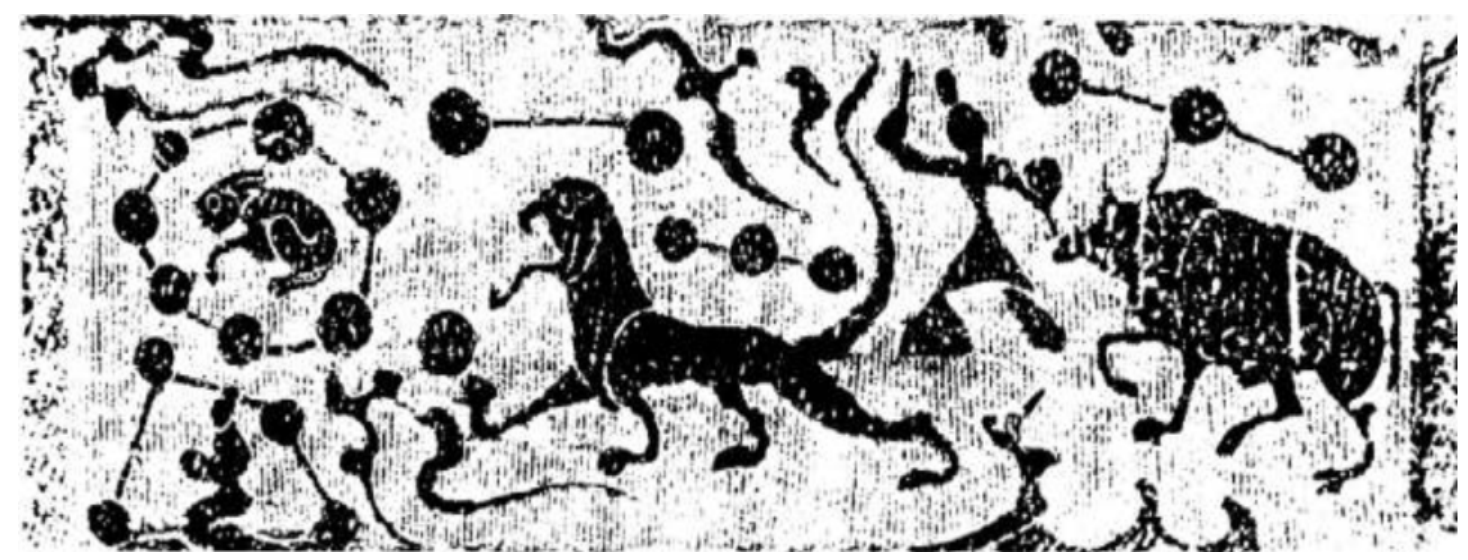

Figure 1. The Niulang and Zhinv in Nan yang, Henan Province, this is an astronomical portrait. The picture is from Chinese Ancient Astronomy in Pictures（中国古天文图录）, Pannai (潘蒻), Shanghai Science and Technology Education Press, 2009, P.15, Figure1.26 


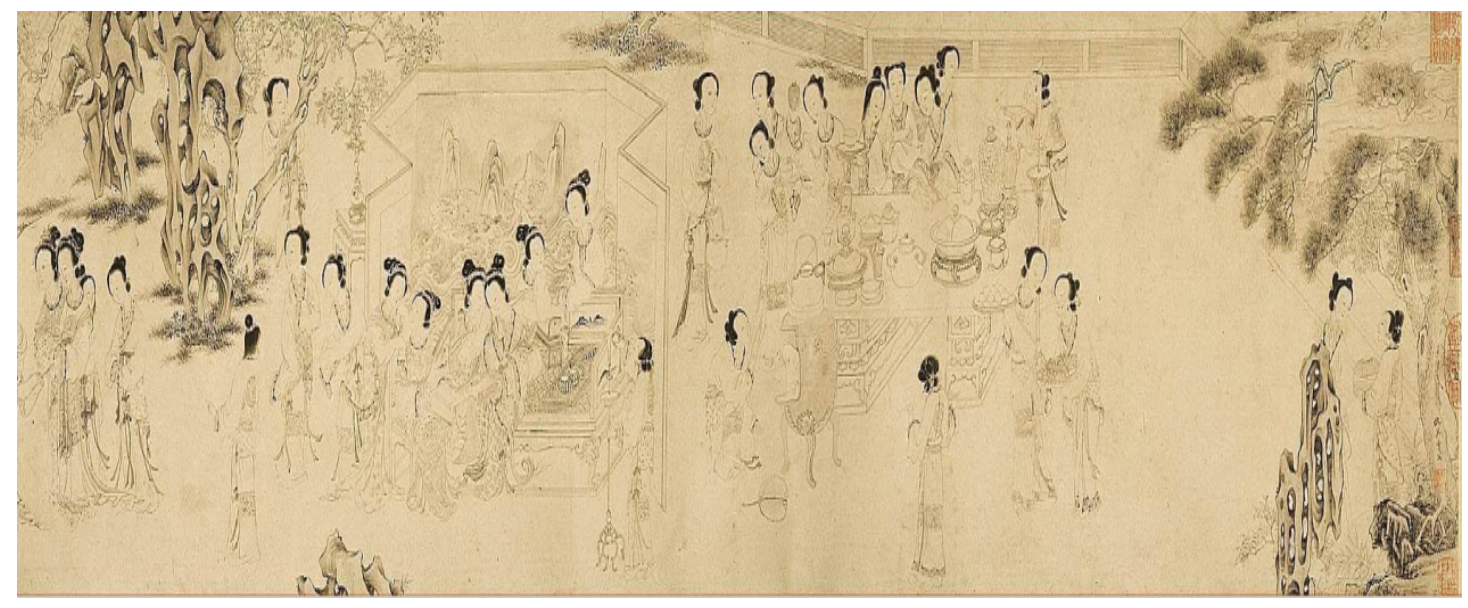

Figure 2. Part of Qiuying's (仇英) The picture of begging dexterousness (乞巧图) in Ming Dynasty, Collection of Taipei Palace Museum

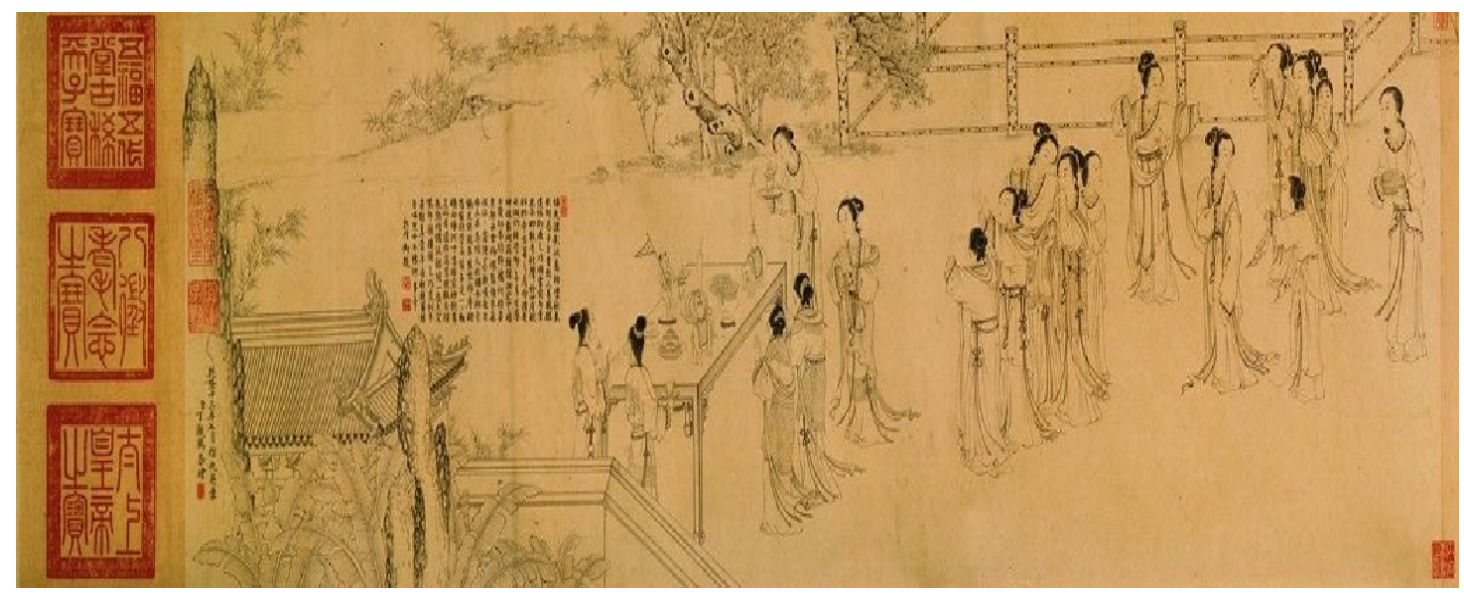

Figure 3. Part of Ding Guanpeng's (丁观鹏) The picture of begging dexterousness (乞巧图) in Qing Dynasty, Collection of Shanghai Museum

Wu Bing'an (乌丙安) pointed out that, the basic elements of the Qixi Festival custom can be divided into three aspects: (1)Oral tradition: talking about the love story of Niulang and Zhinv; (2)The activities of begging for dexterousness: young women perform divination by throwing flower needles, making Qiaoya (巧芽, clever buds), and forming spider webs. There is a competition of threading or embroidering for women; (3)Sacrifice ceremony: people offer the sacrifice to Niulang and Zhinv, eavesdrop on their conversations and catch the tears of Zhinv. (Wu Bing'an, 2014, P.70) But in fact, the activities of celebrate the Qixi Festival has changed a lot over thousands of years. There are a lot of differences in the custom among provinces. The evidence can be found in the local chronicles.

\section{The Custom of the Qixi Festival That Recorded in the Old Local Chronicles}

"The local chronicles are based on a region as a unit (mainly administrative divisions), 
according to a certain style, and comprehensively record the political, economic, cultural and natural books of a certain period of time." (Chinese Local Chronicles dictionary editorial board, 1988, P.1) The compilation of Chinese local chronicles originated very early and it has lasted for thousands of years so far. Almost every province in China has its own local chronicles. Especially the old local chronicles compiled before 1949 are important materials for the study of Chinese history and culture. There are more than 8200 types of old local chronicles preserved, accounting for about $1 / 10$ of the existing ancient books in China. Some scholars believe that the earliest local chronicle appeared in the Wei and Jin Dynasties. At the beginning, it was a kind of local literature written by private individuals and then was compiled by the government after the Sui and Tang Dynasties. It formed a fixed style in the Song and Yuan Dynasties. Eventually, it became a comprehensive local document with a unified structure, diverse categories and rich content in the Ming and Qing Dynasties. Generally speaking, the old local chronicles can be divided into Shengzhi (provincial chronicles), Zhouzhi (State chronicles), Fuzhi (Prefecture chronicles), Xianzhi (County chronicles), and Cunzhi (village chronicles). It recorded the local administrative history, geographical location, mountains, rivers, places of interest, schools, custom, properties, taxes, celebrities, etc. It had the significant regional characteristic. The custom part in the old local chronicles recorded the local custom, folk etiquette, seasonal festivals inherited in the past dynasties. This kind of literature is really helpful to research the Qixi Festival. For example, in the local chronicles compiled during the Ming Dynasty, the Taicang Zhouzhi (太仓州志) which was compiled by Jiangsu Province described that, "On the Qixi Festival, women hold their hair as a thread through the pinhole in the moonlight (七夕，妇女辈以发对月穿针)."

(Zhou Shizuo \& Zhang Yin, 1629, volume 2) The Pingyang Xianzhi (平阳县志) that compiled by Zhejiang Province described that, "On the Qixi Festival, people make a kind of special food named Qiaoshi (巧食), and children cut off the silk thread which was tied to their arms on the Dragon Boat Festival. This behavior is called Huanqiao (换巧) (七夕, 作巧 食, 小儿剪去端午系臂丝线谓之换巧)." (Zhu Dongguang \& Hou Yiyuan, 1571, P.136) The Chongxiu Kunshan Xianzhi (重修昆山县志) which was compiled by Jiangsu Province stated that, "During the Qixi Festival, women dye their nails with impatiens balsa mina, take silk thread to pass through the pinholes in the moonlight, or offer melons and fruits as sacrifices to Zhinvin order to beg for dexterousness (七夕, 女妇以凤仙花染指为饰, 又以丝线对月 穿针或有设瓜果乞巧者)." (Zhou Shichang, 1576, volume 1, P.45) The Xinning Xianzhi (新 宁县志) which was compiled by Hunan Province described that, "On the Qixi Festival, in the courtyard, people display clothes and books under the sunlight to dry them. Children offer melons and fruits as sacrifices in the evening to beg for dexterousness (七夕，晒衣服书帙于 庭, 其夜儿女设瓜果乞巧)." (Wang Chen \& Chen Yuanke, 1545, volume 2) It can be seen that the custom of the Qixi Festival is quite different in different areas. In this research, we take Shanxi Province as an example, starting with the local chronicles that compiled in the Qing Dynasty and the Republic of China, analyzing the custom of the Qixi Festival in its territory in order to look for the differences. 


\section{$\triangle$ Macrothink}

\section{Differences in the Custom of the Qixi Festival Recorded in the Old Local Chronicles}

of Shanxi Province

We sorted out 145 types of old local chronicles that recorded custom materials of Shanxi Province, and found 72 types of them recorded the Qixi Festival. There were 51 books compiled in the Qing Dynasty and 21 books were compiled in the Republic of China, involving 63 prefectures, states, and counties, as shown in Figure 4. According to the blue label in Figure 4, it can be seen that local chronicles that recorded the Qixi Festival were mainly distributed in the southwestern of Shanxi Province, with a total of 55 places. There are only 8 local chronicles can be found in the north of the province that recorded the Qixi Festival. After carefully comparing the contents of the books we found that the differences in the custom of this festival can be divided into 4 categories, i.e., the gender and age of the participants, the sacrificial objects, the sacrificial offering, and the behavior of begging dexterousness.

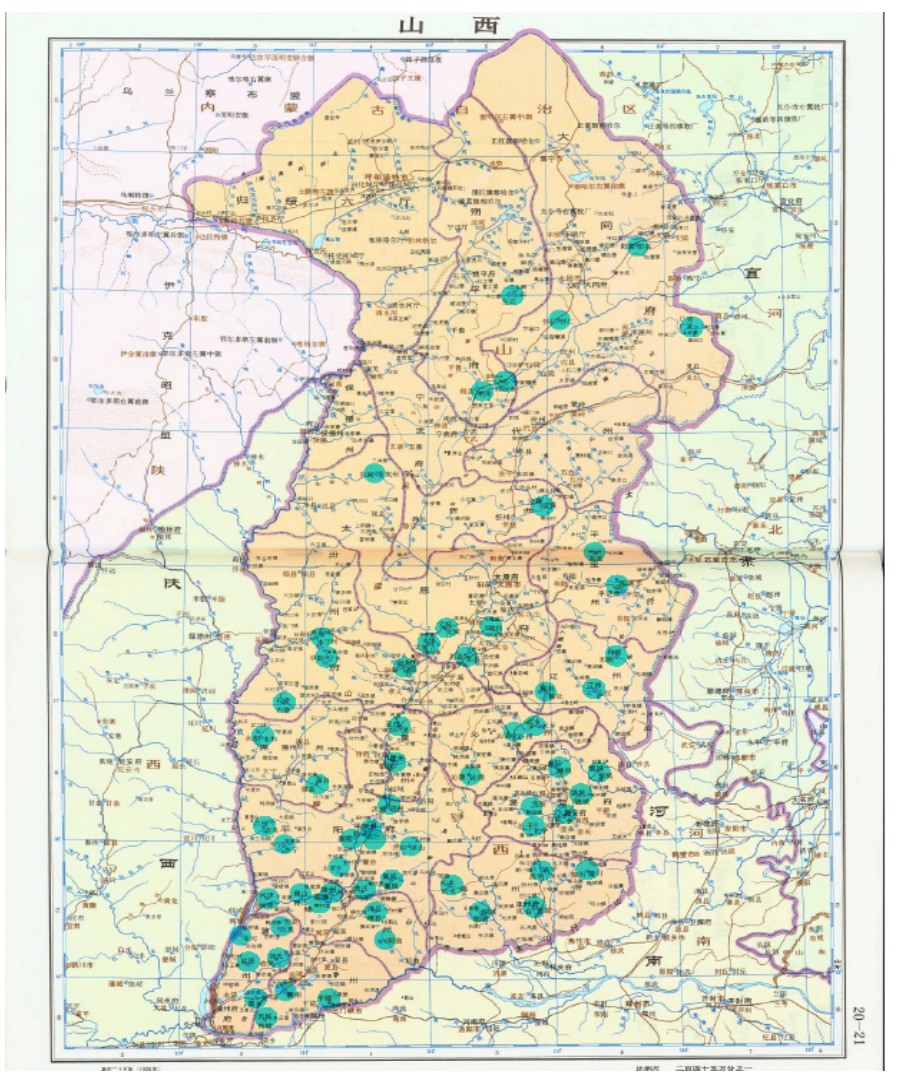

Figure 4. Distribution map of Qixi Festival in Shanxi Province

\subsection{Differences in the Gender and Age of the Participants}

Both male and female are participants in some areas during the Qixi Festival. We classified and counted the participants according to gender, age and other criteria, as shown in Table 1. 
Table 1. Gender and age of the participants

\begin{tabular}{ccc}
\hline Gender & Age and status & How many places were recorded \\
\hline Male & Adult scholars & 4 \\
& Boys & 7 \\
Female & All women & 33 \\
& Virgins or unmarried young & 2 \\
& women & 13 \\
\hline
\end{tabular}

According to the data shown in Table 1, it can be seen that there are fewer male participants and they can be divided into two categories, i.e., adult male scholars and boys. Both of them were accompanied by female participants. The former were recorded in the local chronicles of Kelan State, Haizhou State, Fenyang Prefecture, and Jiangxian County. For example, in the Kelan zhouzhi (岢岗州志) that compiled during the Guangxu(光绪) period of the Qing Dynasty record that, "The scholars write and the women pierce needles, which is called begging for dexterousness (书生执笔, 女子穿针, 谓之乞巧)." (Ding Shiliang \& Zhao Fang, 1989, P.569) The latter was recorded in the local chronicles of Tunliu County, Linfen County, Jixian County, Jiangzhou State, Xinjiang County, Jiangxian County, and Ronghe County. For example, the Linfen Xianzhi (临汾县志) that compiled during the Qianlong(乾隆) period of the Qing Dynasty recorded that "people put melons and fruits on the table as sacrifices at night, boys and girls beg for dexterousness (夜设瓜果筵, 童男女乞巧). " (Ding Shiliang \& Zhao Fang, 1989, P.643) Female participants could be divided into three categories: (1)All women could participate it and there was no special status requirement. This situation occurred in 33 places including Liaozhou State, Zezhou Prefecture, Pingyang Prefecture, Yuxian County, Qixian County, Gaoping County, Yangcheng County, Qinyuan County, Lingshi County. etc. (2) Participants must be virgins or unmarried young women. This situation only occurred in Heshun County and Wuxiang County. For example, the Heshun Xianzhi (和顺县志) that compiled during the Republic of China recorded that, "the virgin put the grains in the pottery to sprout, worship Niulang and Zhinv, and beg for dexterousness (处女用瓦器生五谷芽, 供牛、女乞巧) ." (Ding Shiliang \&Zhao Fang, 1989, P.573) (3) Participants were girls. This situation mainly occurred in 14 places including Shuozhou State, Haizhou State, Huairen County, Yanggao County, Xiangning County, etc. For example, in the Xiangning Xianzhi (乡宁县志) that compiled during the Qianlong period of the Qing Dynasty recorded that "On July 7th, young girls worship the grandson of the god in order to beg dexterousness(七月七日, 幼女祀天孙乞巧)." (Ding Shiliang \& Zhao Fang, 1989, P.682) The grandson of the god means Zhinv here Therefore, in the Qing Dynasty and the Republic of China, although there were male participants in the Qixi Festival in Shanxi Province, but it was mainly a traditional festival with female groups as participants, and in some areas there were strict requirements on the identity of female participants, they must be virgins and girls. 


\section{Macrothink}

\subsection{Differences of Sacrificial Objects}

Among the 72 books we have mentioned above, 26 books pointed out the objects of sacrifice clearly. These 26 books involved 22 regions, and the objects of sacrifice could be divided into two categories: (1)Niulang and Zhinv; (2)Zhinv, as shown in Table 2.

Table 2. Sacrificial objects of the Qixi Festival in Shanxi Province during the Qing Dynasty and the Republic of China

\begin{tabular}{ccc}
\hline & \multicolumn{2}{c}{$\begin{array}{c}\text { Sacrificial objects and the number of local chronicles which } \\
\text { record it }\end{array}$} \\
\cline { 2 - 3 } Era & Niulang\&Zhinv & Zhinv \\
\hline Qing Dynasty & 5 & 11 \\
Republic of China & 7 & 3 \\
\hline
\end{tabular}

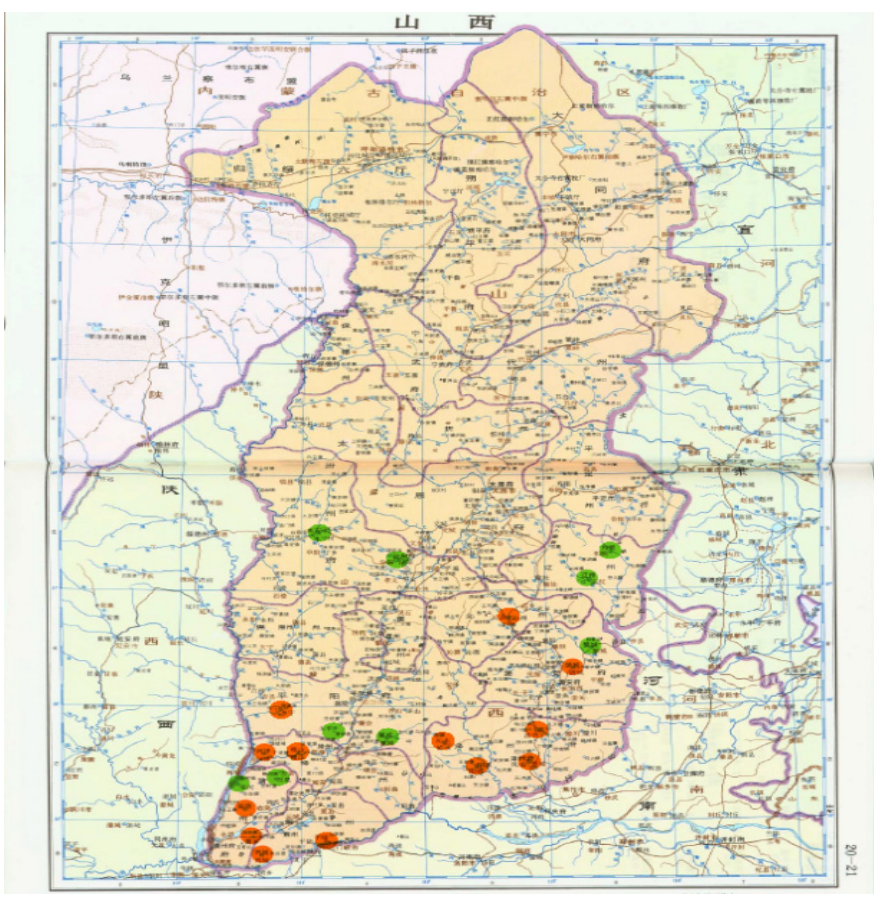

Figure 5. Distribution of Sacrificial Objects of the Qixi Festival in Shanxi Province

As shown in the Table 2 and the Figure 5, the areas with definite sacrificial objects were mainly distributed in the south of Shanxi Province. In Figure 5, the red dots represent the areas where Zhinv was worshipped. There are 13 places in total. The green dots represent the areas where the Niulang and Zhinv were worshipped together. There are 9 places in total. Generally speaking, Zhinv was existed as the core of the object of sacrifice, especially in the Qing Dynasty. Through further analysis of the economy of these places, we found that Lu'an Prefecture, Zezhou Prefecture, Haizhou State, Puzhou State, Pingyang County and Fenzhou Prefecture were all extremely prosperous during the Ming and Qing Dynasties, and the textile 
industry was particularly developed. The Lu silk(潞绸) produced in Lu'an Prefecture was extremely exquisite. "It was not only a tribute to the royal family, but also a kind of commodity that exported overseas（不仅被列为贡品, 而且远销海外). "(Yang Qiumei, 2008, P.264) In addition, many Shanxi merchant families were born in these areas at that time. They brought a large amount of silk fabrics to Henan Province, Gansu Province, Sichuan Province and other provinces to sell. The development of commerce had further promoted the prosperity of the hand-made textile industry. It also raised local residents' attention to worship Zhinv, and regarded her as a symbol of improving skills production and increasing family income. This phenomenon mainly existed in the Ming and Qing Dynasties. After the establishment of the Republic of China, due to the impact of Western cochummodity economy and industrial civilization, the local residents' worship of Zhinvwas gradually weakened. On the one hand, merchants brought a large number of low-priced foreign fabrics back to Shanxi Province for sale, which reduced the sales of local fabrics. On the other hand, the entrepreneur in Shanxi Province began to product fabric by machine at that time. So the requirement for manual weaving skills was no longer as urgent as before. It also meant that people's dependence on Zhinv was no longer as strong as before. In short, folk beliefs were closely related to the prosperity and decline of the local hand-made textile industry in that period.

\subsection{Differences in Sacrificial Offering}

The sacrificial offerings of the Qixi Festival are mainly melons and fruits. People believed that the Zhinvwas in charge of melons and fruits in Sui and Tang Dynasties. A scholar named Du Gongzhan (杜公瞻) in the Sui Dynasty had pointed it out when he explained the book Jingchu suishi ji (荆楚岁时记). Another scholar named Zhang Shoujie (张守节) in the Tang Dynasty said that, "Zhinv is a goddess in the sky, she is in charge of the fruits, silks and treasures of the world (天女也, 主果㼏丝帛珍宝)." (Si Maqian \& Zhang Shoujie, 2004, P.1565) In addition to melons and fruits, people also take wine, flowers, incense, delicate needles, and pastries as sacrifices. Through analyzing the data, we found that 37 prefectures and counties took melons and fruits as sacrifices, such as Liaozhou County, Yongning County, Zezhou County, Qinzhou County, Linfen County, and Changzi County. In Licheng County, Gaoping County, and Yangcheng County, people took melons and wine as sacrifices. In addition, Dingxiang County and Licheng County took flowers as sacrifices. Guangling County, Zuoyun County, and Yishi County offered incense. The most distinctive offerings are the Qiaozhen (巧针) and pastries that enshrined in Yicheng County. Qiaozhen can be used not only as sacrifices, but also as instruments for competition and divination. It can be divided into two types: one is the needle made by metal and the other is needle made by plant. The needle made by metal is very common. On Qixi Festival, in order to increase the difficulty of the threading competition, women often arrange several metal needles in a row to make a seven-hole needle (七孔针) or a nine-hole needle (九孔针). Xijing Zaji(西京杂记) described a story happened in the Han Dynasty that the maids through a seven-hole-needle with a thread in the Kaijin Building (开襟楼, a building in the imperial palace. Kaiyuan and Tianbao Yishi (开元天宝遗事) recorded the story of concubines in the Tang Dynasty hold five-color thread to through a nine-hole needle. Another type of Qiaozhen was made by soaking grains 
such as wheat and beans in water to germinate. People usually start making them one week before the Qixi Festival until the grain had grown a 3 or 4 inch high bud. On the day of the festival, people dedicated it to Niulang and Zhinv at first, and then used it for divination. The production of pastry is relatively simple. People put the pig's head, ink stone, tile, and needlework basket which made of flour into a pot and steam them. The phenomenon of using pasta as a sacrifice is only seen in Yicheng County, which is a unique local custom.

\subsection{Differences in the Activity of Begging Dexterousness}

The activity of begging dexterousness has a specific name called Qiqiao (乞巧) that is people pray to the Zhinv to become smarter and more dexterous. They usually express this psychological appeal during the sacrifice process and the threading competition. These two methods are popular in most places in Shanxi Province. However, in Yicheng County, Linjin County, and Pinglu County, a special ritual was once circulated which was called Duqiao (度 巧). "People choose the youngest girl from the crowd, cover her head with a quilt or cloth; somebody keeps beating the gongs and drums to make a huge sound until the girl feel dizzy for the noise. If she can take the thread to through the needle hole in this moment, this situation is called Duqiao (以最幼女孩, 蒙絮被下, 或用布裹头, 旁以锣鼓震之使昏, 而 犹能作拈针穿线状)." (Ding Shiliang \& Zhao Fang, 1989, P.658) This behavior had great harm to children's hearing, and it was a bad custom which was not been accepted by more areas. Therefore, it was quickly abolished. But the activity, Buqiao ( $卜$ 巧), has been loved by most people for the interesting and divination until nowadays. The specific method of this activity is to put the Qiaozhen (巧针, a needle) or Qiaoya (巧芽, a bud) floated on the water that contained in $\mathrm{Yu}$ (孟). Then people conduct divination according to the shape and size of their reflection in the water, as shown in Figure 6 and Figure 7. For example, the Linjin Xianzhi (临晋县志) which was compiled in the Kangxi (康熙) period of the Qing Dynasty recorded that, "Boys and girls put the sprouts of malt or bean float on the water in the Yu and check the reflection of it in the water. If the reflection is the shape of the nib or the sole of the shoe, it indicates that they have been blessed by the Zhinv. Boys will become scholars in the future, and girls will be good at weaving (儿女掐麦、豆芽尖, 置孟水上, 视针影作笔尖鞋 底之状以为得巧). " (Ding Shiliang \&Zhao Fang, 1989, P.715) In Yicheng County, "people associate the size of the reflection with the amount of blessing gained (视影之大小以为得巧 之多寡). " (Ding Shiliang \&Zhao Fang, 1989, P.651) 


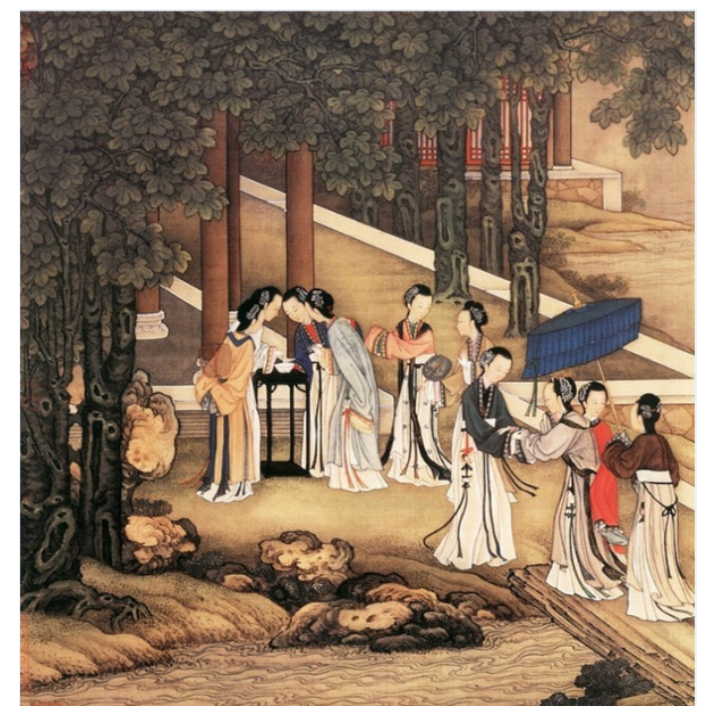

Figure 6. Qixi Tongyin Qiqiao 七月桐荫乞 巧 drawn by Chen Mei (陈枚) in Qing Dynasty, Collection of Beijing Palace Museum

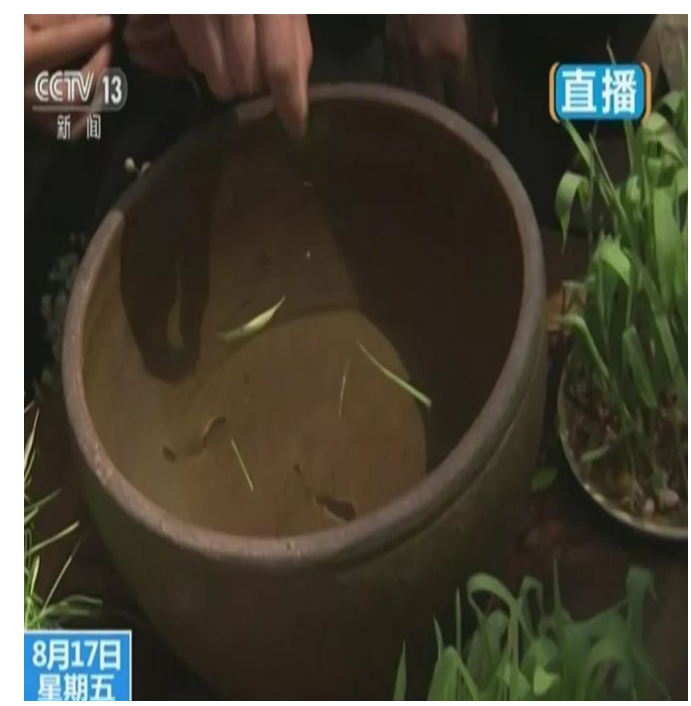

Figure 7 Buqiao activities in nowadays

\section{Results}

The purpose of this study is to explore the relationship between festival custom and natural environment by comparing the differences of the Qixi festival documents recorded in Shanxi's local chronicles during the Ming, Qing and Republic of China periods, to explain the phenomenon that changes in production mode and economic structure will inevitably affect the festival custom and the folk beliefs.

\subsection{Festival Custom Is Influenced by the Natural Environment and the Crops Planted}

The climate in southern Shanxi Province is mild and the soil is fertile. The natural environment there is suitable for planting a variety of crops. During the Ming and Qing Dynasties, farming, weaving, and business were the main production methods of local residents. In some areas of northern Shanxi Province, the harsh environment and the barren soil lead to the crops grow difficultly. Most of the local residents chose to join the army, graze the animals and go hunting to maintain their livelihood. According to the statistics of 63 local chronicles, we found that cotton, mulberry or hemp were widely planted in 55 areas in the south, these plants are essential raw materials for the development of textile industry. In the north, such as Baode State, Ningwu Prefecture, and Daizhou State, people did not grow cotton and mulberry. The Ningwu fuzhi (宁武府志) compiled during the Qianlong period of the Qing Dynasty recorded that the farmers get very little grain each year from farming, and they mainly rely on buying grain, fruit and vegetable from other places. There are no mulberry and hemp here ( 农人岁耕所获盖少, 大半仰食外谷, 虽果蔬亦然, 又无桑柘麻 菒). (Wei Yuanshu \& Zhou Jingzhu, 1750, volume 9) Due to the relatively poor natural environment and the lack of raw materials, the culture of farming and weaving was not 
suitable for development here. As a result, the Qixi Festival, which took spinning and weaving as the important elements could not be widely spread among the people.

\subsection{Changes in Production Mode and Economic Structure Influenced the Festival Custom}

The prosperity and decline of the hand-made textile industry and commerce also affect people's attitude towards the festival as well as the way to celebrate it. During the Ming and Qing Dynasties, the hand-made textile industry in southern Shanxi was generally developed. For example, Taiyuan Prefecture, Fenyang Prefecture, and Jiangzhou State produced a large amount of cotton cloth every year. Lu'an Prefecture and Zezhou Prefecture produced a large amount of silk fabrics. Especially in the Ming Dynasty, almost every household took the loom to produce cloth. During the most prosperous period, "there were more than 13000 looms in Changzhi County, Gaoping County and Luzhou County, ...produced 4790 pieces of silk(长治、高平、潞州卫三处, 共有织机一万三千余张, ...织细四千九百七十匹)." (Zhang Shuqu \& Yao Xuejia, Lu'an Fuzhi, 1770, volume 8, P.100) On the one hand, these silk products were paid tribute to the royal family; on the other hand, they were sold to other provinces and abroad as commodities. Among them, some Lu silk was sold to other minority regimes, such as Mongolia. "In 1571 (the fifth year of Longqing), after the Ming regime reached an agreement with the Mongolian Andahan tribe, there were regular trade between Xuanfu (now Xuanhua, Hebei Province) and Datong (now Datong, Shanxi Province), and Lu silk became one of the important commodities (1571 年（隆庆五年）明政权与蒙古族俺答 汗部达成协议后，在宣府（今河北宣化）、大同（今山西大同市）两地定期举行贸易， 潞绸也成为重要的商品之一)." (Hou Wujie, 1999, P.615) Another part of Lu silk was exported to Xinjiang, Japan, Russia and other places. "Silk trade in China's southwest and northern border areas, as well as silk trade between Ili and Russia, is mainly supplied by camel caravan composed of Shanxi silk traders." (Tian Qiuping, 2015, P.110) In addition to silk, cotton and linen products were also mass-produced. The merchants in Pingyang Prefecture, Lu'an Prefecture and Zezhou Prefecture made a lot of money. They began to do business all over China and became the forerunners of the famous Shanxi Merchants in Ming and Qing Dynasties. During this period, most of the local chronicles of these places recorded the Qixi Festival. The local chronicles of Changzhi County and Gaoping County, which belong to Lu'an Prefecture, and Yangcheng County, which belong to Zezhou Prefecture, recorded the customs of the Qixi Festival in great detail. Generally speaking, the Qixi Festival was popular in the south of Shanxi Province in a wide range. People celebrated the festival in a variety of ways, and the festival was very interesting. As for the northern part of Shanxi, although cotton, mulberry or hemp had been planted but the textile industry was not formed. The Baode Zhouzhi (保德州志) which was compiled during the Kangxi period of the Qing Dynasty recorded that women did not know how to weave linen and cloth. And it also recorded that, "During the Wanli (万历) period of the Ming Dynasty, the chief executive of the prefecture Hunan (胡柚), once taught residents to grow mulberry and raise silkworms, but this was soon abolished. Then another chief executive of this prefecture named Gao Qifeng (高起风) taught the residents to grow cotton and weave but this activity was abolished too (明万历间知州胡柚教以掻桑寻废, 国朝康熙间知州高起凤导之种棉亦寻废)." (Wang Kechang, 1932, volume 3) Therefore, the Qixi Festival, which was closely related to the 
development of the hand-made textile industry, was popular in a small range in the northern region, and the celebration form was relatively simple and unitary. Some counties did not even celebrate this festival. However, after entering the Republic of China (1911), due to the influence of the war, with the introduction of large-scale machine production, and the import of a large number of cloth from abroad, Shanxi's local hand-made textile industry suffered a serious blow. Most people bought imported cloth to make clothes and few people wove cloth by themselves. Taking Wuxiang County as an example, " From 1922 to 1925, 94.5\% of the farmers wore foreign cloth, and the self-sufficiency rate was only 5.5\% (1922 年至 1925 年, 农户衣着洋布所制者占 94.5\%, 自给率仅为 5.5\%)." (Qu Shaomiao \& Pang Yicai, 1984, P.205) Meanwhile, the production of silk had also been greatly reduced. The changes of production mode and economic structure affected people's attitude towards traditional festivals. The records of the Qixi Festival Customs in southern local chronicles especially the worship of Zhinv had weakened a lot.

\subsection{A Variety of Elements Are Integrated, and the Details Are Prone to Change}

The Qixi Festival incorporates myths, legends, sacrifices, competitions, and divination. It is a comprehensive festival with commemorative, competitive and interesting features. However, because of this diversity, the holiday custom will partial variety when some factors are missing or changed. Taking sacrifices as an example, since the Qixi Festival is usually in summer or autumn, and the folks can offer ripe fruits to Niulang and Zhinv to express gratitude and pray for blessings. But for those places where fruits are not abundant, the way local residents celebrate the Qixi Festival is obviously different.

\section{References}

Chinese Local Chronicles Dictionary editorial board. (1988). Chinese Local Chronicles Dictionary. Hangzhou: Zhejiang People's Publishing House.

Ding, Shiliang \& Zhao Fang. (1989). Compilation of Chinese Local Chronicles and Folklore Materials • North China Volume. Beijing: Bibliography and Literature Publishing House.

Hou, Wujie. (1999). Historical Records of Shanxi Province. Beijing: The Commercial Press.

Qu, Shaomiao, \& Pang,Yicai. (1984). Shanxi Foreign Trade Records. Taiyuan: Office of Shanxi Local Chronicles Compilation Committee.

Si, Maqian, \& Zhang, Shoujie. (2014). Shiji. Beijing: Zhonghua Book Company.

Tian, Qiuping. (2015). Overseas Lu merchants. Taiyuan: Shanxi Publishing and Media Group · Beiyue Literature and Art Publishing House.

Wang, Chen, \& Chen, Yuanke. (1545). Xinning Xianzhi. Block-printed edition of the twenty-fourth year of Jiajing in the Ming Dynasty.

Wang, Kechang, \& Yin, Menggao. (1976). Baode Zhouzhi. Printed in 1932, collected in Chinese Local Chronicles Series • North China. Taiwan: Chengwen Publishing Co., Ltd.

Wei, Yuanshu, \& Zhou, Jingzhu. (1750). Ningwu Fuzhi. Block-printed edition of the fifteenth year of Qianlong in the Qing Dynasty. 


\section{Macrothink}

Wu, Bing'an. (2014). Folk Heritage Review. Changchun: Changchun Publishing House.

Yang, Qiumei. (2008). Shanxi History and Culture. Taiyuan: Shanxi Publishing Group • Sanjin Publishing House.

Zhang, Shuqu, \& Yao, Xuejia. (2005). Qianlong Lu'an Fuzhi. Printed in 1770, collected in Chinese Local Chronicles Collection - Shanxi Prefecture and County Annals. Nanjing: Phoenix Publishing House.

Zhou, Shizuo, \& Zhang, Yin. (1629). Taicang Zhouzhi. Reprinted edition of the second year of Chongzhen in the Ming Dynasty.

Zhou,Shichang. (1983) Chongxiu Kunshan Xianzhi. Printed in 1576, collected in Chinese Local Chronicles Series • North China. Taiwan: Chengwen Publishing Co., Ltd.

Zhu, Dongguang, \& Hou, Yiyuan. (1983). Pingyang Xianzhi. Printed in 1571, collected in Chinese Local Chronicles Series • North China. Taiwan: Chengwen Publishing Co., Ltd.

\section{Copyrights}

Copyright for this article is retained by the author(s), with first publication rights granted to the journal.

This is an open-access article distributed under the terms and conditions of the Creative Commons Attribution license (http://creativecommons.org/licenses/by/4.0/) 